Article

\title{
Academic Policy Regarding Sustainability and Artificial Intelligence (AI)
}

\author{
Muhammad Tanveer ${ }^{1}\left[\right.$, Shafiqul Hassan ${ }^{2, *} \mathbb{C}$ and Amiya Bhaumik ${ }^{1}$ \\ 1 Lincoln University College, Kota Bharu 15050, Malaysia; cans_tanveer@hotmail.com (M.T.); \\ amiya@lincoln.edu.my (A.B.) \\ 2 Prince Sultan University, Riyadh 66833, Saudi Arabia \\ * Correspondence: sHassan@psu.edu.sa
}

Received: 10 September 2020; Accepted: 27 October 2020; Published: 12 November 2020

\begin{abstract}
Artificial intelligence (AI) has grown, and technologies have intensified across all fields of life, particularly in education. AI has been applied to resources to improve skills giving teachers the time and freedom to provide understanding and adaptability and drive performance. This paper, written for policymakers in the field of education, highlights the impact of AI and advancements in academic policy. These academic policymakers generate ideas and strategies for applying AI across various disciplines. There is also discussion around AI implementation in education throughout developing nations for moving towards and ensuring affordable, high-quality education for every individual. Education for sustainable development (ESD) aims to promote the development of knowledge, skills, understanding, values and actions necessary to build a sustainable world, to protect and preserve the environment, and promote social equity and economic sustainability. This paper analyses how AI can be used to update learning probabilities by providing examples of how it can be integrated with existing educational systems, using data to improve educational capital and quality in developing countries. It goes on to discuss whether policymakers and institutions can reinvent and rework educational programs to polish graduates' skills for the growing presence of AI across all disciplines. There are four main parts to this work: (1) different dimensions regarding the complexities and potential implications, (2) the pros and cons of educational sustainability policy related to AI, (3) carving out AI and its outstanding execution, and finally (4) the linkage of AI with higher education within the context of educational expansions. In conclusion, the paper focuses on AI's applications, benefits and sustainable development education challenges.
\end{abstract}

Keywords: university education; academic policy; educational system; educational sustainability; artificial intelligence and higher education

\section{Introduction}

Artificial intelligence (AI) [1] refers to the simulation of human intelligence in machines that are programmed to think like humans and mimic their actions [2]. AI is an increasingly technical field that can even transform the way we socialise. AI is everywhere--it exists in innovative teaching and learning methodologies and it is studied in various contexts. AI requires complex technology and a vibrant, innovative community. Yet, what about the urgencies for AI in developing nations? Could AI resolve the issues caused by physical and social gaps in these nations? These are among the questions explored in this paper.

Historically, AI was developed as an academic field in 1955, and there was excitement at first, followed by a lack of funding and disappointment. AI research began in 1956 in a workshop at Dartmouth College, where John McCarthy coined the word "artificial intelligence" to differentiate from cybernetics, and to evade Norbert Wiener's influence [3]. 
From its commencement at the Dartmouth discussion in 1956, AI has drawn attention in business and technology [4]. Few technological advances have been as steadily unattended as AI. Although AI has existed for almost 60 years, it has remained a niche technology until recent fundamental changes known as "the great leap". The great leap brought computer abundance (big data), computational resources, economic exposure and developments in machine learning. This report focuses on AI and analytics, the latest decade's major technology buzzwords, and other topics in which algorithms and learning analytics are relevant, being innovations that are fit for each other.

While there is no clear and accepted definition of AI, numerous works of literature offer variations on the definition, including [5].

The study of artificial intelligence is to proceed based on the conjecture that every aspect of learning or any other feature of intelligence can in principle be so precisely described that a machine can be made to simulate it [6,7].

$\mathrm{AI}$ is progressing rapidly in the current age and having a great impact on the higher education sector. Universities are already using and benefiting from the AI of the IBM Watson supercomputer. IBM Watson offers assistance to students at Deakin University in Australia at any time of day, 365 days of the year [8]. AI is integral for university "outsourcing" using intelligent machines [9].

\section{Literature Review}

AI is a branch of computer science concerned with building smart machines that are capable of performing and even outperforming human jobs. The development of $\mathrm{AI}$ is shaping a growing assortment of sectors. AI is predicted to affect global productivity [10], equivalence and enclosure [11], eco-friendly outcomes [12] and numerous other areas, in both the short-and long-term [13,14]. AI has proven its position in a variety of fields as a game-changing force, triggering unprecedented transformations. Expert systems using AI can be programmed to communicate with the world through capacities such as visual intuition, speech recognition and smart actions that we consider to be inherently human.

There is comprehensive literature on the theory and practice of reasoning in AI. Researchers have investigated the growth, logical reasoning and qualitative temporal theoretical properties of AI [15]. For example, AI growth in Pakistan is attracting significantly however, contemporary national policy has also produced conditions in which private sector enterprises have gained considerable influence and agency within regional development networks [16]. Private education institutions have taken advantage of these favorable political conditions to develop, expand and apply AI technologies to their specific areas of extracurricular provision [17]. AI can also be applied in countries according to their cultural values and wealth. Advanced AI technology, research and resources are available through large computing centers, which have very high-energy requirements [18].

\subsection{Dimensions of $A I$}

The dimensions of AI are discussed in the following sections.

\subsubsection{Judging Humanly}

In the complete and literal sense, this is the new and exciting attempt to make machines "feel" through AI as with brains [19]. AI serves and inserts factors that influence our thoughts and how our actions can be implemented. This includes the automation of activities that we associate with human thinking, activities such as decision-making, problem solving and learning [20].

\subsubsection{Behaving Humanly}

The action of developing machines to perform tasks once performed by humans requires creativity [21]. The emergence of AI and its growing impact on many sectors necessitates an assessment of its effect on the attainment of sustainable development [22]. AI includes the study of how machines do activities that humans can do better [23]. 


\subsubsection{Thinking Logically}

To build AI that thinks logically, computer scientists must investigate cognitive skills via computer simulations [24]. Specific calculations can enable perceiving, reasoning and acting. Logical thinking and AI efforts to influence human wisdom. AI is not only capable of processing numerical data, but also learning human wisdom-based operations.

\subsubsection{Acting Logically}

Acting logically is the process of acting systematically to achieve given goals and beliefs.

Computational intellectual capacity is the analysis of the intelligent operative design [25]. Acting logically is difficult to achieve, as stated by Vinuesa and colleagues:

“On the other hand, it may also lead to additional qualification requirements for any job, consequently increasing the inherent inequalities, and acting as an inhibitor towards the achievement of this target [26]".

$\mathrm{AI}$ is influenced by a knowledge artefact attitude [27]. Figure 1 illustrates judging humanly in an attempt to make machines feel and behave like humans thinking logically and acting logically.

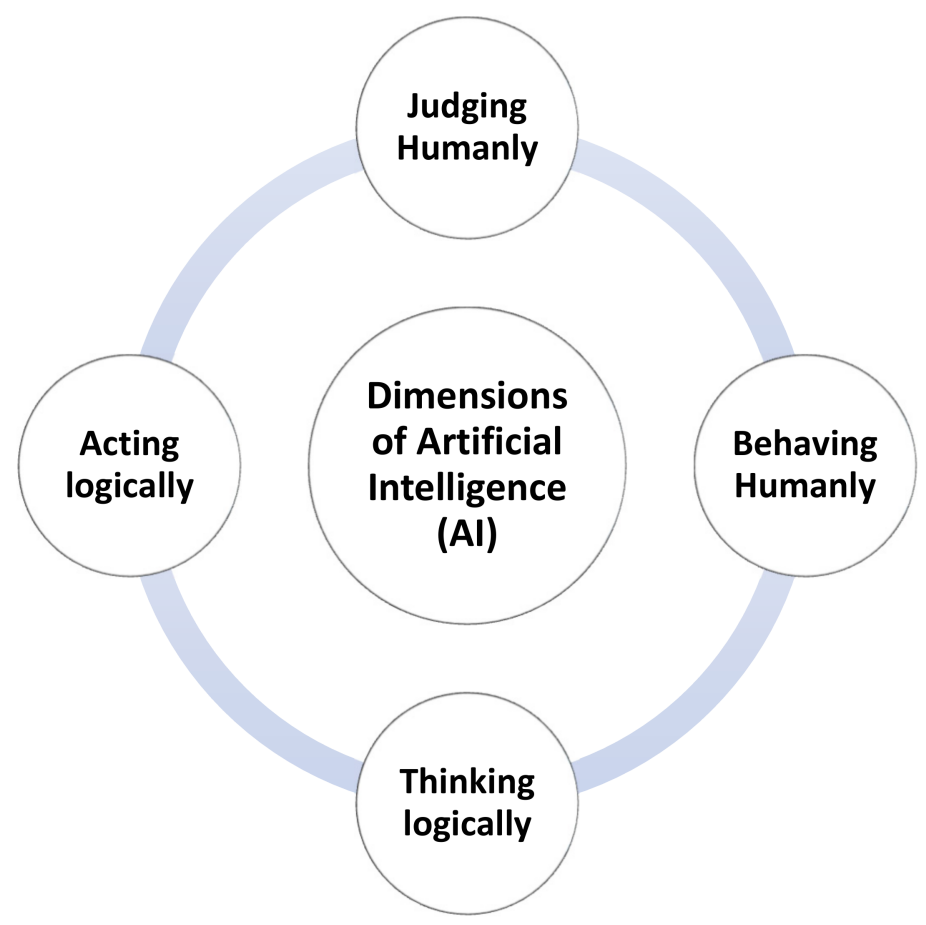

Figure 1. Developed by author through literature.

\subsection{The Concept of Machine Learning and Analytics}

The concept of AI is to address how we should create information systems that systematically evolve with practice. So, the question is: what are the simple laws concerning all learning methods? The term AI is commonly used in reference to any kind of programmed machine learning [28]. It is starting to replace "big data" and its "advanced analysis" and "predictive analytics". In general, machine-learning algorithms may decide how and where to handle important functions [29]. Deep learning is software development that builds a computer's scientific knowledge (and art) so that it learns from digital records and data to make decisions independently of humans [30]. It endows applications with just the power to read and respond to computer authoring tools. Machine learning is the process of achieving AI. It is also worth noting that without the use of machine learning, AI is still possible, but it would involve the construction of millions of coding and decoding structures. 


\subsection{Clarification}

Figure 1 illustrates that judging humanly means attempting to make machines feel, think logically and act logically like humans. Work in AI has concentrated primarily on both the aforementioned elements of competence (understanding, thinking, data analysis, comprehension) and use of words. There are two forms of AI: statistics-driven AI and information-dependent AI. Both are centred on an abstract description of technical knowledge that a system is affecting. Most of AI's recent success can be attributed to advancements in statistics-driven AI. In 1959, just a few years after AI's emergence, Arthur Samuel coined the term "machine learning", describing the idea as "the ability to understand without specific programming" [31].

Deep learning is another commonly used term, being one of several machine-learning methods. Some alternative methods of deep learning include learning from the algorithm, inductive logic coding, clustering, confirming analysis and Bayesian systems. Deep learning is a machine-learning subfield. It is a new advancement to data learning representations that emphasises the learning of continuous levels of progressively significant depictions.

AI flourishes with information. With more information, the outcomes of AI systems become more reliable. Big data allows AI to stand on its own feet; without big data there can be no databased AI. A contemporary illustration of the term big data is a group of data sets with size far beyond the capability to collect, store, handle and analyse typical database software techniques [31].

Academic data analytics and curriculum management are two specific areas where machine learning is used in academic courses. Data mining is a subject in computer science that defines the process of finding interesting and informative trends and interactions in vast amounts of information. Educational data mining (EDM) creates approaches and employs mathematical, machine learning and data analysis strategies to analyse data obtained while teaching. Learning analytics (LA) is the assessment, compilation, review and reporting of learner data and their contexts to understand and improve the learning process effectively. The objective is to scale up the real-time use of LA by students, teachers/scientists and virtual school systems to improve the contributions of students at both the course and personal levels.

\section{Using AI to Improve Performance and Productivity}

Though AI has been facing many issues in the education sector, part of the problem is the hesitation of this sector to transform conventional methods into technological systems. AI became part of the narrative of improving schooling through the development of tutoring programs that could customise education. This is beginning to change as technology advances, with new models around the globe questioning $\mathrm{AI}$ in the field of education. The next section outlines examples of government policies, entrepreneurial commitments and corporate sector projects in mounting economies, as a peek into the initial phases of AI-integrated educational measures.

\section{Promoting Personalisation and Optimising Learning Outcomes}

AI can promote interactive learning. Among the most revolutionary elements of collective education supported by technology is that seen in situations when participants are not in the same location practically. This gives vector options for students to choose when and where they want to learn. Online discussion groups also play an important role in machine-supported interactive learning.

AI frameworks used to track distributed group discussions have focused on AI technologies such as machine learning and seamless document analysis while supplying educators with knowledge about student conversations or facilitating learner interaction and understanding. Teaching staff spend too much time on regular and logistical activities, including creating homework and addressing frequently asked questions (FAQs). Using a dual-teacher design featuring an instructor and a remote substitute teacher who can perform most of the teacher's daily role, teachers have more time to concentrate on student instruction and one-on-one contact. 
Computer-assisted learning (CAL) provides options to virtual and AI learning approaches for students [32]. Using technologies to support students across various content pathways with the aid of their schools and teachers, AI can tailor education and maximise learning opportunities. As reported recently, smart, continuing education structures are part of current technical opportunities for expanding education in underdeveloped countries [33].

A great deal of time is spent on exams and assignments, so AI could be used as an analysis tool to rate instructors and save time. AI not only works for automating repetitive classification tasks, but also for examining papers in data analytics in education management information systems (EMIS) and for evolving learning management systems (LMS).

Overall, EMIS is an ideological movement of information and data systems that collaborate, process, archive, interpret and transmit strategic planning knowledge in the education sector. These data systems are commonly used at state, municipal and academic levels for political officials, decision-makers and administrators, and for the collection of official statistics. Applied to student performance testing data, results-driven decision making (DDDM) is a focus of many college and community initiatives, partly due to state- and federal-based transparency strategies. A structured and conceptual EMIS helps participants throughout all school-sector grades to obtain helpful information to organise and apply a system of education more effectively, create realistic and value-effective strategies, devise appropriate initiatives and track and analyse academic performance. In nations where information is comprehensive, trustworthy, consistently collated, analysed and stratified, EMIS will have tougher skills and the capacity to analyse facts and figures instantly and produce data analytics from school, state and federal levels. EMIS even opens up the prospect of creating lookup tables for policymaking.

\section{Youth to Grow with AI in the Coming Years}

Overall, businesses are quick to adopt solutions based on AI, suggesting an investment in new job types and abilities connected to a sector's use of AI. As such, the education sector has a clear need to react to rework teaching methods and revise regulations. No country on earth is prepared for smart automation. Even professionals in the system, as a logical answer to smart automation, are only beginning to emerge.

\subsection{A Modern Framework for a Future Driven by the Internet and AI}

Training plays a key role in making future, intelligence-ready workplace initiatives. Striking a balance in AI capabilities goes beyond introducing evermore effective learning-friendly innovations. In many universities, AI has penetrated and has led the growing concern that intelligent machines will soon replace many human beings. This article explores the complementarity of humans and AI, to offer a more constructive and realistic viewpoint on how everyone can contribute their power in context. This includes evaluating the curriculum and approaches that are used to provide training at all educational institutions. Hybrid learning is an educational model in which some students attend classes directly, while others attend remotely. Educators simultaneously instruct remote and onsite students using hardware and software for video conferencing [34].

\subsubsection{Frameworks of Digital Skills}

A core concept of data literacy is:

The capacity to securely and properly navigate, handle, recognize, incorporate, interact, analyse and generate content across mobile devices and enabling technology for social and economic activity. It involves skills that have been known as computer literacy, information communication technology literacy, knowledge literacy and intercultural communication [34].

Overall, the information below reveals the skills needed, characterised as a function of this structure. In collaboration with big private players, for example Cisco, the International Society for Technology in Education, Microsoft and Intel, the Communication and Information Technology 
Proficiency Formula for Teachers (ICT CFT) was created by the United Nations Educational, Scientific and Cultural Organization (UNESCO) in 2011, and it was revised and updated in 2018. This system defines the skills that instructors now have to incorporate through their educational policies to improve essential awareness in participants.

Transmedia connects directly to changing educational needs in this transformative age. It not only helps students learn to use AI-led resources, but also to live and interact in a world of hybrid societies of human and digital agents. Furthermore, the system underlines the role of computer technology in serving the following six primary information areas:

1. Curriculum and evaluation;

2. Comprehension of information and communication technology (ICT);

3. Pedagogy;

4. Practiced education for professionals;

5. Organisation and establishment.

The program identifies three levels of gaining knowledge:

The European Digital Competence Framework or Dig Comp (Joint Research Centre, 2018) is another framework developed by the European Union (EU) to contribute to the professional development of an individual's technical capabilities. The framework maintains that the language is critical, and requires new technology in an integrated, effective, interactive and useful way to encourage people to achieve their objectives of service, research, leisure, inclusion and digital community engagement. The system is organised into five areas of expertise that define the essential components of technological skills, namely knowledge and software literacy, connectivity and interaction, digital media creation, security and critical thinking. It considers these aspects and traces them across four skill levels, including basic, advanced, qualified and highly skilled [35].

\subsubsection{Computational Thinking (CT)}

CT came to light as one of the key skills to boost teachers to prosper in a community operated by AI. The Computer Science Teachers Association in the United States of America (USA) describes CT as a major issue-resolving method for the activities indicated below:

1. Helping solve difficulties using a computer and other equipment;

2. Rationally arranging and collecting data;

3. Using templates and models to depict data;

4. Streamlining answers using the algorithms (a series of ordered steps);

5. Determining, examining and applying solutions to accomplish the most efficient and productive variety of paths and infrastructure; and

6. The major issue-solving method extended and generalised to a broad range of things (International Association of Engineering Teachers of Learning and Computer Science, 2011).

Therefore, although it clearly belongs to the computer-engineering realm, CT is an ability that has roles in other areas. Due to the growing use of AI in working environments, CT has become a crucial skill for educators to come to terms with adjusting learning needs to the employment market. Therefore, many states have started to incorporate CT into their core curriculum.

Computer thinking uses heuristic data to find solutions in the face of uncertainty to learn and prepare. It is our collated searches that lead to a list of webpages-a winning strategy in computational thinking. Large volumes of data in time and space, processing power and storage capacity all contribute to computing thinking.

A State Commission survey revealed that while national governments of the EU are at different stages of incorporating CT into their national curricula, they have all started to work on it. Regarding the levels of CT integration in curricula around the world, the study [35] found three groupings: 
1. Curriculum reform and modernisation began (during the last three to five years) in the United Kingdom France, Portugal, Italy and Finland;

2. Planning for integration of CT into the core curriculum in Denmark, Finland, Norway and the Czech Republic; and

3. Long records of practical education in Austria, Poland and Lithuania.

\subsection{Building AI Capacity through Post-Basic Training and Education}

There is a rising number of countries that have already created a comprehensive plan for AI. China, France, and as of recently, the USA have comprehensive strategies that cover initiatives conducted by businesses to innovate and incorporate new products and services and conduct research and development $(R \& D)$. The development process is often the first step. It shows the inordinate impact in the training of workers competent in AI. Overall, R\&D encourages engagement in tertiary studies. By contrast, Finland has made choices through the development of a larger platform to easily achieve these goals of AI literacy, reaching one percent of their total workforce.

\subsection{Higher Education and $A I$}

$\mathrm{AI}$ is hypothetically, and early in practice, officially entering the higher education realm. One of the key strategies used by policymakers to resolve specific skill gaps is to develop AI skills across science and research. Most countries are looking to make AI science and practical careers more appealing to increase their skills in AI and become innovators.

\subsection{Technical and Vocational Education Training (VET) and AI}

VET organisations must also be able to offer systems that integrate AI-associated skills, particularly if they are planning and aiming to develop students with expertise that is adapted to the workforce. Long-term literacy in some countries is mentioned in practical skills training and services for adult learning. Thus, lifelong learning encompasses these and other policies, and it includes a broad spectrum of measures. Germany and Singapore have specific training plan structures. In Germany, eligible people looking for work or already employed may collect teaching gift cards from their corresponding engineering firm or workplace to use for appropriate training and professional development. Such grants are available at universities that are approved for further education (Federal Ministry of Employment and Foreign Affairs, 2012).

\section{AI induction in Education-Challenges and Implications for Policy}

AI-powered providers have become widespread in many parts of the world, including the poorest countries. For example, in Kenya, robots are used for secure, discreet and anonymous responses to questions concerning family planning and for connecting people to medical professionals. These robots depend on AI technology. AI programs have also surfaced across many countries in the African farming sector.

Monetary and public freight sectors are further examples of areas where AI-powered technologies are changing people's lives. Tala is the number-one competition for financing in Kenya. It provides low-interest mortgages and clear arrangements on reimbursement. There seems to be no installing loan with potential customers. This demonstrates that even under harsh conditions, innovation is possible. Some scholars have built a structure for analysing health-conscious developments as developed through necessity under challenging conditions.

Questions being asked both by foreign aid and government policies include: How might developing countries with crippling social health issues cope with the intricate ecosystem in literacy that is necessary for AI solutions to grow? Why would government policy inspire instructors as being are central performers and not just bystanders? In developing countries, AI in education is 
often ignored as a component of a technologically advanced dialogue that guides a securely educated workforce and knowledge ecosystem service.

The final section of this report discusses the six key challenges of integrating AI throughout schooling, as both a way of improving wealth and academic value and encouraging knowledge. It covers the second main point of this article: $\mathrm{AI}$ as a new learning experience, and how schooling can support students and potential employees in an AI-powered environment. Figure 2 brings together the areas that AI have infiltrated in the education sector.

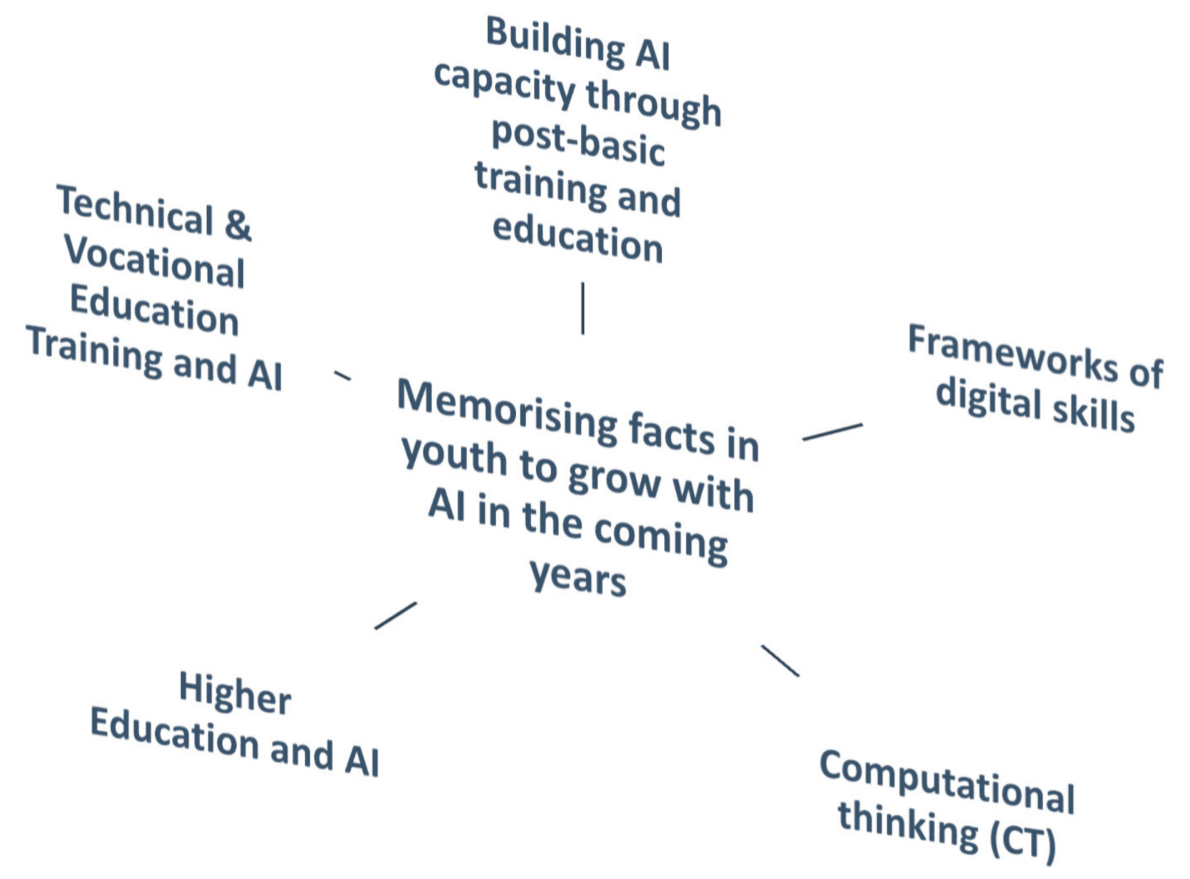

Figure 2. Developed by the author, deduced through literature.

$\mathrm{AI}$ is the perfect combination of something artificial with intelligence that makes it capable of learning. In addition, so many different views have been expressed about AI, and shown below are some of society's most important assessments against AI. Figure 2 shows the aspects of AI in the coming years, which are derived from the discussion made earlier. Figure 2 also presents the framework of AI induction in education.

\subsection{An Extensive AI Policy for Sustainability}

In the face of rapid advances in AI-powered technologies, the education industry is both a consumer and a user. As seen in France, China, Australia, Denmark, South Korea, Singapore and the USA, the educational dimension is crucial as companies grow international AI initiatives. AI has fantastic potential to increase educational systems; yet, the question is: how might AI help students, professors, administrative staff and lawmakers? Educational standards must provide students with the necessary skills to function in an AI-rounded society. Organisations including IBM, DreamBox, Pearson, Smart Sparrow, McGraw Hill, LightSide, Knewton, Coursera and Cerego are also making good progress in incorporating personalised research across smart technologies that customise studying using analytics.

AI deals with information, creativity, industry and new restrictions inside diverse systems. Analysts have predicted that the machine learning market will grow by 50 percent between 2017 and 2021. What were different countries' position, in a sense? Can these countries deal with the stress of the speed of private markets driving changes in technology? For developing countries, the best way to answer these burning questions is via more research. 
To introduce the benefits of AI into education, governments must solve problems concurrently to produce ideas and policies and build or promote environments for creativity. Education policy implementation for $\mathrm{AI}$ is still in its adolescence, but it is likely to increase rapidly over the next decade. This is challenging in these early stages, as there are several holes in policy that need to be filled. Several policymakers are beginning to expand people's understanding and political debate on these topics to build a diverse environment for AI and for collective good. Throughout this process, it is vital to seek advice from experts and form teams to design plans, guidelines and policies that cover the following:

- Laws, policies and government institutions capable of dealing with AI in the field of innovation;

- Policies to protect private companies' use of AI in terms of security uses, anonymity and accountability of how architectures are developed;

- Policy for the educational and ethical implications of AI.

New national sector organisations and institutions are essential for maintaining economic development in a conceptual AI sense. The development of academic and research labs for student training, as well as training of AI professionals, are important to build new work opportunities. Research into AI is also underway in many countries:

- Regions are building labs and fertility clinics with state funds as part of plans to establish AI programs supporting government services;

- Regions are building labs and research labs with public money as part of plans to establish AI programs supporting essential services.

Collaborations between academic institutions can speed up AI competence growth. An important component of improving the AI curriculum and testing is public-private collaboration. Countries listed in this document have formed alliances between industry and government to exchange content and political power, as well as to ensure that training programs are well-matched with the needs of the workforce. Nevertheless, collaborations should never be confined to specific disciplines; intra-sector alliances are just as relevant as inter-sector alliances.

\subsection{Ensuring Enclosure in Employment and Equality in AI}

Equity and inclusion should be core values in the design of AI policies for education. Legislators must ask a set of questions regarding inclusion and equity when developing their reforms. For example, what environments and infrastructure are urgently needed in emerging countries to make AI possible in literacy? What have we learned from past observations, in terms of internet connectivity, to create secure and equal requirements for internet privacy? Numerous studies have plotted the barriers to introducing $\mathrm{AI}$ in academic achievement in underdeveloped countries. The major ones are the affordability and availability of:
1. Electricity;
2. ICT hardware;
3. Student basic ICT capabilities;
4. Data;
5. Culturally sensitive subject matter;
6. Language;
7. Internet robustness [33].

\subsection{Training of AI-Enabled Educators and Students to Grasp Learning}

There is no evidence of process-wide adoption of AI-based learning and teaching, including for systems management, even if new developments have yet to be halted by the educational software industry. Their fundamental problem is that they endorse new avenues for coordinating education 
that conflict with conventional approaches, instead of discussing the current problems and challenges facing students. There needs to be more detailed tests to reflect the possible benefits of new approaches.

Faculty training is a vital parameter for motivating them to seek guidance from instructional data to trace pedagogy and encourage pervasive use of $\mathrm{AI}$ in the classroom. That said, AI-enabled systems already offer incentives to eliminate some of the repetitive and logistical duties educators perform, including marking and maintaining records. Optimising these activities will free up instructors' resources, motivating teachers to dedicate greater attention to their organisation's artistic, empathic and stimulating facets.

\subsection{Value Production and Functional Data Systems}

Since data fuels AI, trustworthy and expeditious data are a mandatory requirement to installing increased big data systems for AI. A functional data analysis program with thorough and up-to-date data provides opportunities for probabilistic and computational modelling algorithms that have been enabled by AI. No algorithm, no matter how complex, will function correctly with incorrect data. A statistics-rich environment is, therefore, a necessity for AI-enabled programs. Nonetheless, the quality of data is a requirement that is essential but inadequate. AI-enabled programs are only as strong as the information they comprise. It is important to note that the education system is not the only database for information on the quality of education. The UNESCO Institute for Statistics (UIS) is the official and trusted source of internationally comparable data on education, science, culture and communication. Thus, residential results from UIS can also provide clues into extenuating factors that account for school teaching hardships.

\subsection{The Relevance of AI Concepts and Research-Based Education}

There is now a tremendous need to endorse AI technologies in learning in terms that serve to make society better adapted to AI-driven economic needs and practices. Ensuring efficient learning of AI is not only a question of resources, but also of measuring and assessing what works in training--distributing it in formats that are accessible to instructors and ideal for optimisation. The current issue is to understand AI usage and how it can contribute to educational achievement. This can be discussed using parallels and organised gradually with systematic studies and tests to create a reliable body of knowledge.

Instead of saying more research is required, the implication is that research needs to be directed with specific goals in mind. In learning, the so-called "prevalent associations" have had an omnipotent problem-the total number of associations that expand the uncertainty of separating impacts or merging the effects of published research papers. Since the impacts of instruction approaches are very difficult to eliminate, any explanation of strategies for optimising performance will reflect student skills and abilities, social class, encouragement and the connections between these. Because education anomalies are complicated and nuanced, the relevant questions are not whether to include AI in learning; the question is which AI technologies will help address the changing learning needs that instructors are tackling in the classroom, while taking into account circumstances and prospects [36]. If universities or organisations plan so that they spend less and get more, they will be successful and able to maintain and sustain success [37]. Nonetheless, in using AI, the real disruption of education is yet to come.

\subsection{Transparency in Collecting Data}

AI has many important implications; however, there are social and ethical issues that need attention. Many people read about arbitrarily biased AI programs [38] that are trying to take existence-impact life choices in a semi-transparent manner, anticipating to take all of our vacancies [31] and take control of the population (The Register, 2018). In discussions on ethical data standards, data protection comes up almost immediately. The challenge is the willingness to use personal details while preserving the safety of personally identifiable information and privacy preferences. In addition, it is critical to install 
safeguards to discourage data theft. This becomes even more difficult in a school setting with young learners who, legally speaking, are unable to give written consent to the processing and use of their personal data [39].

\section{Conclusions}

Until now, the private industry has taken AI as a guiding light in most regions of the world. Technology giants of the USA and China dominate in the race to advance AI-enabled growth. The rapid growth of start-up companies has also played a key role in increasing AI acceptance. Particularly significant is the continued expansion of the EdTech sector, with AI-enabled learning tools in use throughout classrooms. Moreover, given the enormous impact of AI on all aspects of life, increasing numbers of policymakers can systematically introduce practical strategies to AI. Several nations have even published national AI plans, such as Denmark, China, France, Australia, the USA and South Korea. Research is a comprehensive element in any of these responses.

Unavoidably, AI is an industry that drives innovation, thereby enhancing the profitability of jurisdictions. Education and AI have penetrated the business sector, creating both socio-economic and economic opportunities. As robots become cheaper and more advanced, they move to new industries from their traditional roles in operations. The future of almost every industry and every human being is exaggerated by AI. The main drivers of emerging technologies, such as big data, robots and the Internet of Things are all part of AI and will continue to be technological innovators.

However, there is also space left for information sharing, the premise of which is experience sharing. It is now time to gather more information about how countries can move forward with this unsure and continuously evolving territory to promote collaborations and adopt detailed AI interpretations in the education sector. This can be a forum for community engagement and peer networking to build an AI education "aurora" to look at AI projects in communication and advise on national and international AI policy proposals. This observation tower (with a strong emphasis on the developing world) will help boost the dialogue between decision-makers, based on empirical evidence. The report concludes that the proposals of AI put forward are important starting steps that can direct the development of a real policy system. Certainly, engaging sectors in developing such a paradigm is critical, as AI's impact spreads across areas of the economy.

Moreover, as shown by the examples listed in this paper, multiple responses can be seen to the revisions that accompany the emergence of $\mathrm{AI}$ in respective disciplines of human movement. As evidence to the hypothesis, recently, a conference was scheduled to highlight the impact of studying AI on the progression of Pakistan [40,41].

Author Contributions: Main contribution to writing—original draft, M.T.; writing—review, S.H.; editing, M.T.; supervision, A.B. All authors have read and agreed to the published version of the manuscript.

Funding: All authors of this article would like to thank the Governance and Policy Design Research Lab of Prince Sultan University for their financial and academic support to conduct this research and publish it in Sustainability.

Conflicts of Interest: The authors declare that there is no conflict of interest.

\section{References}

1. Turing, A.M. Computing Machinery and Intelligence; Oxford University Press: Oxford, UK, 1950. [CrossRef]

2. Simmons, A.B.; Chappell, S.G. Artificial Intelligence-Definition and Practice. IEEE J. Oceanic Eng. 1988, 13, 14-42. [CrossRef]

3. Buchanan, B.G. A (very) brief history of artificial intelligence. Ai Mag. 2015, 26, 53.

4. Cummings, M.L. International Security Department and US and the Americas Programme. Artificial Intelligence and the Future of Warfare; Chatham House: London, UK, 2017.

5. McCarthy, J.; Minsky, M. A proposal for the dartmouth summer research project on artificial intelligence. Al Mag. 2006, 27, 12.

6. Russell, S.J.; Norvig, P. Artificial Intelligence: A Modern Approach, 3rd ed.; Prentice-Hall: Upper Saddle River, NJ, USA, 2010. 
7. Gao, J.; Huang, X.; Zhang, L. Comparative Analysis between International Research Hotspots and National-Level Policy Keywords on Artificial Intelligence in China from 2009 to 2018. Sustainability 2019, 11, 6574. [CrossRef]

8. Deakin University. IBM Watson Now Powering Deakin. A New Partnership That Aims to Exceed Students' Needs. 2014. Available online: http://archive.li/kEnXm (accessed on 18 April 2020).

9. Grove, J. TeachHigher 'Disbanded' Ahead of Campus Protest. Times Higher Education. 2 June 2015. Available online: https:/www.timeshighereducation.com/news/teachhigher-disbanded-ahead-campusprotest (accessed on 18 April 2020).

10. Acemoglu, D.; Restrepo, P. Artificial Intelligence, Automation, and Work; National Bereau of Economic Research: Cambridge, MA, USA, 2018.

11. Bolukbasi, T.; Chang, K.-W.; Zou, J.; Saligrama, V.; Kalai, A. Man is to computer programmer as woman is to homemaker? Debiasing word embeddings. Adv. Neural Inf. Process. Syst. 2016, 29, 4349-4357.

12. Norouzzadeh, M.S.; Nguyen, A.; Kosmala, M.; Swanson, A.; Palmer, M.S.; Packer, C.; Clune, J. Automatically identifying, counting, and describing wild animals in camera-trap images with deep learning. Proc. Natl Acad. Sci. USA 2018, 115, E5716-E5725. [CrossRef]

13. Tegmark, M. Life 3.0: Being Human in the Age of Artificial Intelligence; Random House Audio Publishing Group: New York, NY, USA, 2017.

14. Courtland, R. Bias detectives: The researchers striving to make algorithms fair. Nature 2018, 558, 357-360. [CrossRef]

15. Oke, S.A. A literature review on artificial intelligence. Int. J. Inform. Manag. Sci. 2008, 19, 535-570.

16. Tanveer, M.; Hassan, S. The role of new and creative ideas in developing industries of education, software and manufacturing in Pakistan. J. Entrep. Educ. 2020, 23.

17. Knox, J. Artificial intelligence and education in China. Learn. Media Technol. 2020, 45, 298-311. [CrossRef]

18. Jones, N. How to stop data centres from gobbling up the world's electricity. Nature 2018, 561, $163-166$. [CrossRef] [PubMed]

19. Hageland, J. Artificial Intelligence the Very Idea; Mit Press: Cambridge, MA, USA, 1985.

20. Bellman, R.E.; Zadeh, L.A. Decision-Making in a Fuzzy Environment. Manage. Sci. 1970, 17. [CrossRef]

21. Kurzweil, R. The Age of Intelligent Machines; Mit Press: Cambridge, MA, USA, 1990.

22. Vinuesa, R.; Azizpour, H.; Leite, I.; Balaam, M.; Dignum, V.; Domisch, S.; Felländer, A.; Langhans, S.D.; Tegmark, M.; Nerini, F.F. The role of artificial intelligence in achieving the Sustainable Development Goals. Nat. Commun. 2020, 11, 233. [CrossRef]

23. Rich, E.; Knight, K. Artificial Intelligence; Tata Mcgraw-Hill: New Delhi, India, 1991.

24. Charniak, E.; Riesbeck, C.K.; McDermott, D.V.; Meehan, J.R. Artificial Intelligence Programming; Psychology Press: New York, NY, USA, 2013.

25. Poole, D.; Mackworth, A.; Goebel, R. Computational Intelligence: A Logical Approach; Oxford University Press: New York, NY, USA, 1998.

26. Nagano, A. Economic growth and automation risks in developing countries due to the transition toward digital modernity. In Proceedings of the 11th International Conference on Theory and Practice of Electronic Governance-ICEGOV', Galway, Ireland, 18 April 2018.

27. Nilsson, N. Artificial Intelligence: A New Synthesis; Elsevier: Amsterdam, The Netherlands, 1997.

28. Chou, J.S.; Ngo, N.T.; Chong, W.K. The use of artificial intelligence combiners for modeling steel pitting risk and corrosion rate. Eng. Appl. Artif. Intell. 2017, 65, 471-483. [CrossRef]

29. Domingos, P. A Few Useful Things to Know about Machine Learning. Commun. ACM 2012, 55, 78. [CrossRef]

30. Géron, A. Hands-on Machine Learning with Scikit-Learn and Tensor Flow: Concepts, Tools, and Techniques to Build Intelligent Systems; O’Reilly Media, Inc.: Sebastopol, CA, USA, 2017.

31. Manyika, J.; Chui, M.; Brown, B.; Bughin, J.; Dobbs, R.; Roxburgh, C.; Byers, A.H. Big Data: The Next Frontier for Innovation, Competition, and Productivity. Available online: https://www.mckinsey.com/ business-functions/mckinsey-digital/our-insights/big-data-the-next-frontier-for-innovation\# (accessed on 16 April 2020).

32. Schittek, M.; Mattheos, N.; Lyon, H.C.; Attström, R. Computer Assisted Learning. A Review. Eur. J. Dental Educ. 2001, 5, 93-100. [CrossRef]

33. Nye, B.D. Intelligent Tutoring Systems by and for the Developing World: A Review of Trends and Approaches for Educational Technology in a Global Context. Int. J. Artif. Intell. Educ. 2015, 25, 177-203. [CrossRef] 
34. Tanveer, M.; Karim, D.; Mahbub, A. Higher Education Institutions and the Performance Management. Library Philosophy and Practice (e-journal). 2018, p. 2183. Available online: https://digitalcommons.unl.edu/ libphilprac/2183 (accessed on 16 April 2020).

35. Hilbert, M. Big Data for Development: A Review of Promises and Challenges. Dev. Policy Rev. 2015, 34, 135-174. [CrossRef]

36. Hoodbhoy, Z.; Hasan, B.; Siddiqui, K. Does Artificial Intelligence Have Any Role in Healthcare in Low Resource Settings? J. Med. Artif. Intell. 2019, 2, 13. [CrossRef]

37. Tanveer, M.; Karim, D.; Mahbub, A. The Use of Performance Measurement in Universities of Pakistan. Library Philosophy and Practice (e-journal). 2019, p. 3010. Available online: https://digitalcommons.unl.edu/ libphilprac/3010 (accessed on 16 April 2020).

38. ProPublica. Machine Bias. 2016. Available online: https://www.propublica.org/article/machine-biasriskassessments-in-criminal-sentencing (accessed on 18 April 2020).

39. Raissi, M.; Perdikaris, P.; Karniadakis, G.E. Physics informed deep learning (part I): Data-driven solutions of nonlinear partial differential equations. arXiv 2017, arXiv:1711.10561.

40. Komal, A.S. Artificial Intelligence (AI), Machine Learning (ML) and Implications for Pakistan. Available online: https://thesvi.org/svi-in-house-seminar-panel-discussion-report-artificial-intelligence-ai-machinelearning-ml-and-implications-for-pakistan-august-20-2019/ (accessed on 21 April 2020).

41. Tanveer, M.; Bhaumik, A.; Haq, I.U. Pakistani Universities and Leadership Reconnoitering the Prospects of Furtherance. J. Seybold Rep. 2020, 15, 10.

Publisher's Note: MDPI stays neutral with regard to jurisdictional claims in published maps and institutional affiliations.

(C) 2020 by the authors. Licensee MDPI, Basel, Switzerland. This article is an open access article distributed under the terms and conditions of the Creative Commons Attribution (CC BY) license (http://creativecommons.org/licenses/by/4.0/). 